\title{
Editorial
}

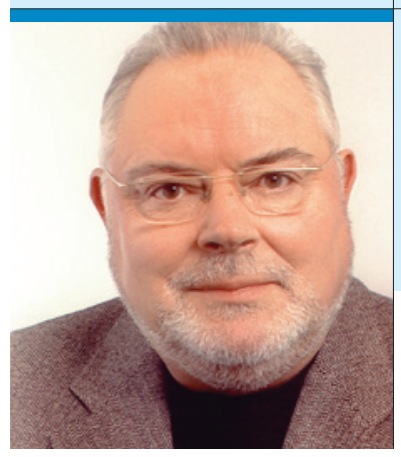

„Ein friedliches Weihnachtsfest und ein hoffentlich

besseres neues Jahr wünscht Ihnen das gesamte

Redaktionsteam der HNO-Nachrichten."

Dr. med. Dieter Leithäuser

Chefredakteur und niedergelassener HNO-Arzt, Warburg

\section{HNO-Weihnachten 2010}

$\mathrm{E}$ in bekanntes Gedicht über die Beamtenkinderweihnacht beginnt mit der Zeile:

Der Gabentisch war öd und leer, die Kinder saßen blöd umher...

Weiter will ich gar nicht orginalgetreu zitieren, es könnte zotig enden.

Doch bei einem Blick auf unser heißgeliebtes HNO-Fach und die jüngsten gesundheitspolitischen Entwicklungen sind nun am Jahreswechsel 2010/2011 gewisse Assoziationen mit dem leeren Gabentisch der Beamtenkinder einfach nicht zu übersehen.

Auch wenn wir nicht blöd rumsitzen, der HNOGabentisch ist nun mal leer, wir bilden mit den Anästhesisten das Schlusslicht bei den Ärzteumsätzen. Und was hat man uns in früheren EBM-Zeiten nicht alles nachgesagt. Die HNO-Ärzte bekämen durch die Sonderleistungen jeden Handgriff bezahlt, hieß es. Zugegeben, wir haben in den Jahren 1999 und 2000 auch noch leistungsorientierte Honorare für unsere differenzierte Tätigkeit bekommen. Heute müssen wir uns dagegen mit der roten Laterne abfinden. Begrenzte Fallzahlen und ungerechte RLVs sitzen uns im Nacken.
Kann man wenigstens hoffen, dass im nächsten Jahr alles besser wird? Ein einsames Adventslicht flackert immerhin schon. Die Ordinationsgebühr wird bei der KV Westfalen-Lippe um 10\% angehoben. Soll man nun zufrieden sein, oder auf den Stichtag 11.11.11, 11:11 warten? Vielleicht gibt's dann was Schöneres als was Schönes oder schlicht nur Narretei wie bisher.

Wie auch immer, Weihnachten und der Jahreswechsel stehen vor der Tür. Und wenn wir Ihnen schon keine guten Nachrichten über einen reich gedeckten Gabentisch liefern können, so wollen wir doch zumindest eines nicht versäumen: das Redaktionsteam der HNO-Nachrichten, einschließlich aller Beiräte wünscht unseren treuen Lesern ein friedvolles Weihnachtsfest und ein hoffentlich besseres Neues Jahr.

Ihr

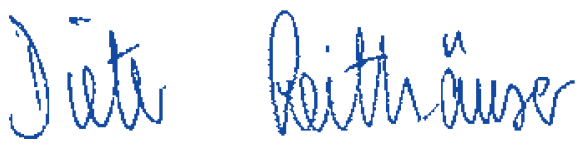

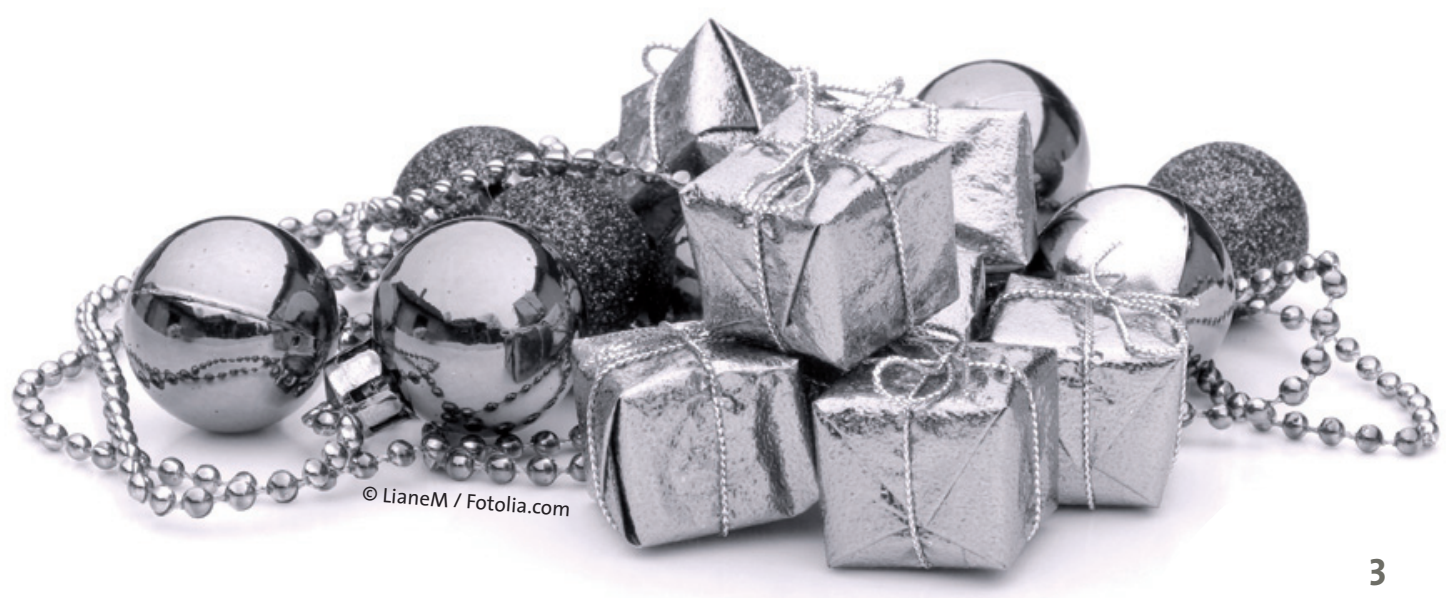

